\title{
Etiological subtype
}

INSERM

\section{Source}

INSERM. (1999). Orphanet: an online rare disease and orphan drug data base. etiological subtype. ORPHA:377795

Subdivision of a disease, malformation syndrome, morphological anomaly, biological anomaly or particular clinical situation in a disease or a syndrome further defined by its aetiology. 